\title{
TINJAUAN ELEMEN DESAIN PADA DUNIA SENI
}

\author{
Aris Darisman \\ Desain Komunikasi Visual, School of Design, BINUS University \\ Jln. K.H. Syahdan No. 9, Palmerah, Jakarta Barat 11480 \\ adarisman@binus.edu
}

\begin{abstract}
Article is a review respected to the elements that are very familiar not even be released in the culture and the visual language-especially the world of art: line, shape, mass, color, value, space, motion. The discussion is limited to the issue of lines because it is one of the most important visual elements and fundamental. The purpose of research is to trace the application of visual elements in art. The methodology used is library research, experiences, and comparative works. Results and discussion form of qualitative analysis. So, it can be concluded that there is a deduction about correlation and function of the visual elements in the art world.
\end{abstract}

Keywords: design elements, arts

\begin{abstract}
ABSTRAK
Artikel merupakan tinjauan terkait elemen yang sangat akrab dan bahkan tidak dapat dilepaskan dalam budaya dan bahasa visual - terutama dunia seni; Garis (line), Bentuk (Shape), Massa (Mass), Warna (Color), Kedalaman (Value), Ruang (Space), Gerak (Motion). Pembahasan akan dibatasi pada persoalan garis (line), karena hal tersebut adalah salah satu elemen visual yang paling penting dan mendasar. Tujuan penelitian adalah untuk menelusuri aplikasi elemen visual dalam dunia seni, metodologi yang digunakan melalui studi pustaka, pengalaman, dan perbandingan karya. Hasil dan bahasan berupa analisis kualitatif, sehingga dapat ditarik simpulan tentang korelasi dan fungsi elemen visual dalam dunia seni.
\end{abstract}

Kata kunci: elemen desain, dunia seni 


\section{PENDAHULUAN}

Sebagai awal bahasan, kita akan melihat gambar berikut.

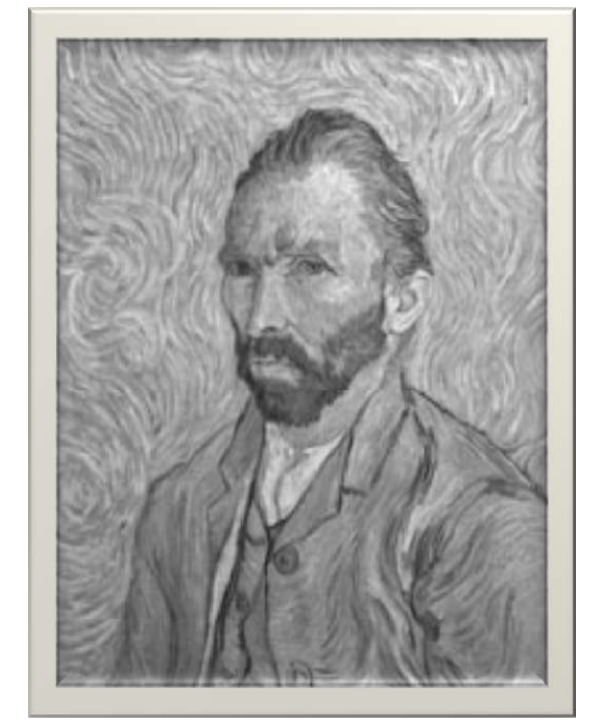

Gambar 1 Self Portrait, Vincent Van Gogh

Ketika kita melihat ilustrasi di atas, maka kita akan dengan cepat mengatakan bahwa itu adalah gambar seorang laki-laki paruh baya. Kita semua tahu bahwa itu bukanlah sosok seorang lakilaki sebenarnya, hanya berupa representasi tarikan kuas dan cat pada sebuah kanvas. Ini adalah karya seorang pelukis besar asal Belanda, yang sebagian besar hidupnya dilewatkannya dalam masa-masa sulit, bahkan sampai akhir hayatnya, Vincent Van Gogh. Dalam lukisannya ini dia menggambarkan sosok dirinya sendiri (self portrait).

Mari kita luangkan sedikit waktu untuk lebih mengamati tentang bagaimana lukisan tersebut dikonstruksikan. Kita dapat melihat bahwa Vincent Van Gogh menggunakan garis (line) dalam menggambarkan bagian kepala, menunjukkan alur rambut, lipatan kain pada bajunya, kerut murung pada wajah, sampai pada tarikan-tarikan kuas pada bagian latar figure. Melalui tarikan garis tersebut, dia menciptakan sebuah bentuk (shape) yang akhirnya menampilkan wujud wajah, bahu, dada, dan lengan bagian atas. Bagian wajah memiliki kualitas permukaan (texture) yang nampak kuat.

Warna-warna (colors) pada lukisan terlihat begitu cerah, terdiri dari paduan dua warna analog (analogue colors), dengan tarikan kuas yang pendek-pendek. Hal tersebut dikarenakan sang seniman hidup dalam 'dua masa', yaitu pada saat gelombang Impressionisme masih begitu bergeloranya, lewat pemujaan warna dan cahaya, namun sekaligus ada ketidaklaziman dalam penggambarannya, terutama pada ekspressi wajah figure yang tampil tidak menyenangkan - murung atau 'mengganggu'.

Vincent Van Gogh melahirkan ekspresi visual yang melampaui masanya pada saat itu, faktor yang begitu kuat dicurigai sebagai penyebab mengapa dia hidup menderita sampai hari akhirnya, namun begitu besar justru setelah kepergiannya. Para pengamat seni mengotakkan penggayaan lukisan dia dalam sebuah istilah 'Post-Impressionime'. Penggayaan yang menjadi jembatan antara era sebelumnya, Impressionisme menuju era yang lebih emosional, Ekspressionisme. Layaknya seorang komposer, Vincent sedang meramu notasi menjadi sebuah karya lagu yang muram namun sekaligus megah, sebuah orkestrasi visual yang menggetarkan. Bagaikan seorang penulis, Vincent sedang mengolah kata-kata menjadi sebuah karya pusi yang indah melenakan namun sekaligus getir. 
Dalam dunia visual kita menamakan bahan tersebut sebagai Elemen Visual. Apa pun jenis karyanya, di mana pun dan kapan pun diciptakan, karakter dari elemen-elemen ini, dan bagaimana itu semua diramu, menjadi penentu karya seni seperti apa yang akan tercipta. Pembahasan ini mencoba meninjau pendekatan elemen-elemen visual yang lazim dipakai pada dunia desain dalam sudut pandang seni. Untuk dapat lebih memudahkan, pembahasan akan 'dibantu' dengan menampilkan contoh-contoh karya dari seniman maupun desainer ternama.

\section{METODE PENELITIAN}

Metode penelitian yang digunakan melalui studi referensi, pengamatan dan analisis karya seni, pengumpulan data untuk dianalisa. Pembahasan dititikberatkan lebih pada persoalan form dan bagaimana hal tersebut disusun berdasarkan kata kunci di atas. Teknik pengumpulan data dilakukan dengan metode studi literatur dan pengalaman.

\section{HASIL DAN PEMBAHASAN}

\section{Garis (Line)}

Secara sederhana garis dapat didefinisikan sebagai jejak yang ditinggalkan oleh pergeseran atau perpindahan sebuah titik. Buatlah titik pada secarik kertas, kemudian gerakkan titik tersebut melintasi bidang gambar, maka akan terbentuklah sebuah garis. Dalam dunia seni, garis adalah sesuatu yang sangat mendasar, sangat sukar untuk dibayangkan ketika sebuah karya seni tidak terdiri atau tercipta dari garis-garis. Ketika kita masih berumur balita, elemen yang pertama kita kenal dalam berkomunikasi secara visual adalah garis. Dengan bebasnya tangan si balita menentukan titik, kemudian menarik garis, begitu bebasnya pula si balita menerjemahkan tarikan garisnya.

Ketika kita menuliskan nama kita, membuat tandatangan atau inisial dari nama kita, maka pada saat itu pula sadar atau tidak kita sedang menarik atau membuat garis. Pada lukisan Vincent Van Gogh di atas, terdapat garis pada wajah figure. Manusia tidak memiliki garis di sekeliling wajahnya, pada kenyataannya wajah manusia terkomposisi melalui material daging dan tulang. Mata kita melihat atau menangkap garis imajiner. Jadi, Vincent Van Gogh menarik garis pada lukisannya sebagai simbolisasi dari wajah. Berdasarkan sejarah perkembangan seni rupa dunia, pemanfaatan garis tepi (outline) untuk menggambarkan sebuah objek dimulai pada era Art Nouveau (1890-1910).

\section{Fungsi Garis}

\section{Garis Tepi dan Bentuk}

Pada lukisan studi bentuk kuda milik Leonardo da Vinci di atas, tarikan garis yang begitu sensitif dari sang pelukis, berhasil membawa persepsi kita pada kesepakatan makna, bahwa tarikan garis tersebut menjelma menjadi sebuah objek yang kita kenal sebagai "kuda". Dari sekian banyak jenis binatang, mamalia, berkaki empat, herbivora, persepsi kita merujuk pada satu jenis nama binatang. Kesamaan atau ketepatan persepsi tersebut dihasilkan oleh kemampuan sang seniman dalam penguasaan keahlian dan ketepatan dia menarik garis. Ini dikenal sebagai gambar outline atau garis tepi. Garis-garis tersebut tidak hanya hadir di bagian tepi gambar, namun juga lewat tarikannya, sensitifitas dalam pengaturan kerapatan, dan kerenggangannya yang begitu terjaga menjelma menjadi shading / bayangan dan juga menjadi interior dari sosok seekor kuda. Pada lukisan Vincent Van Gogh, garis menjadi semacam pembatas. Fungsi garis sebagai garis tepi tidak dapat dielakkan lagi menjadi sangat penting. 


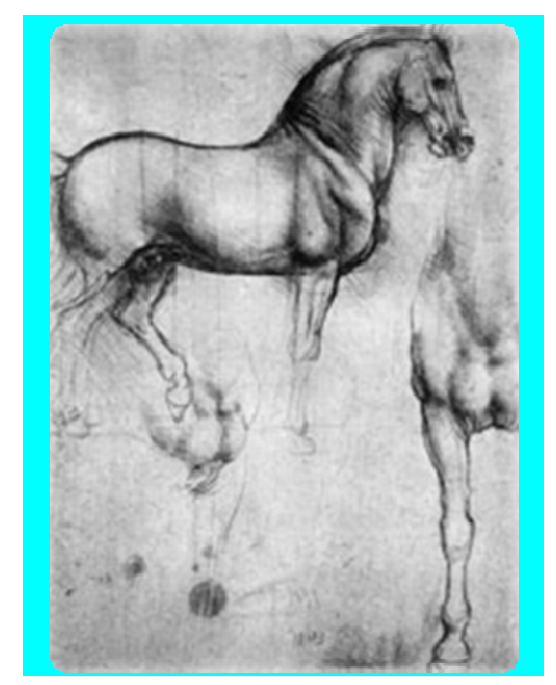

Gambar 2 Leonardo da Vinci, Horse Study

Jika Da Vinci menciptakan ilusi tiga dimensional dalam karya studi Kuda, maka yang dilakukan oleh Alexander Calder, seorang seniman patung, pada karyanya yang berjudul $113^{\text {th }}$ birthday, adalah justru lewat medium tiga dimensional (patung bermaterial kawat) menawarkan persepsi dua dimensional. Penggunaan garis untuk menciptakan bentuk yang memang tiga dimensional.

Karya patungnya terdiri dari sejumlah material kawat yang ditekuk dan digabungkan sedemikian rupa sehingga membentuk atau menyerupai tarikan-tarikan garis. Lukisan da Vinci berasal dari medium dua dimensional yang kemudian melahirkan kesan tiga dimensional, karya Alexander Calder berasal dari medium tiga dimensional mencari arah pendekatan dua dimensional. Kedua karya tersebut mamanfaatkan kekuatan garis.

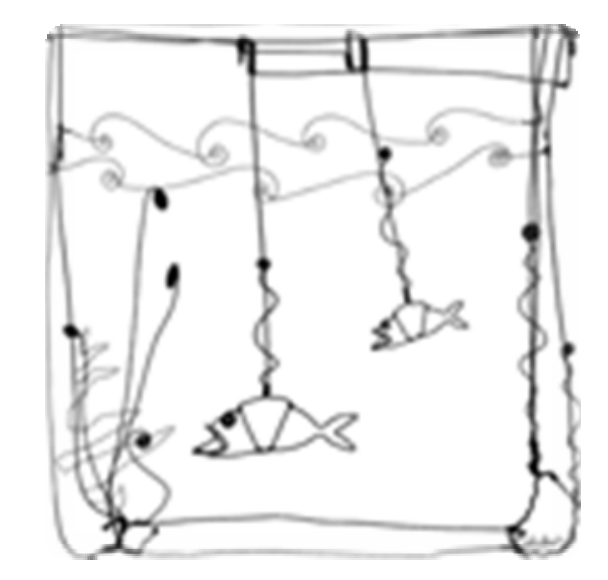

Gambar 3 Alexander Calder, $113^{\text {th }}$ birthday

\section{Movement dan Emphasis}

Pengertian sederhana dari movement adalah gerak, di mana mata kita diarahkan menuju satu titik tertentu lewat komposisi elemen visual. Emphasis lebih kepada focal point, atau point of interest dari sebuah komposisi visual. 
Fungsi lain dari garis adalah untuk menyiratkan gerakan. Setiap garis menuju arah tertentu, dan mata kita secara alami mengikutinya. Garis juga memegang peranan dalam menciptakan emphasis dalam sebuah karya seni. Pada lukisan Claude Monet, Rue de la Bavolle, deretan rumah di sisi kiri kanan jalan Bavolle membentuk sebuah garis maya perspective menuju titik tengah kanvas. Artinya, melalui garis maya perspektif tersebut, Monet mengajak mata kita untuk mengarahkan pada satu focus perhatian, yaitu figure seorang laki-laki berjalan seorang diri dan di bagian depan nampak seorang ibu beserta anaknya.

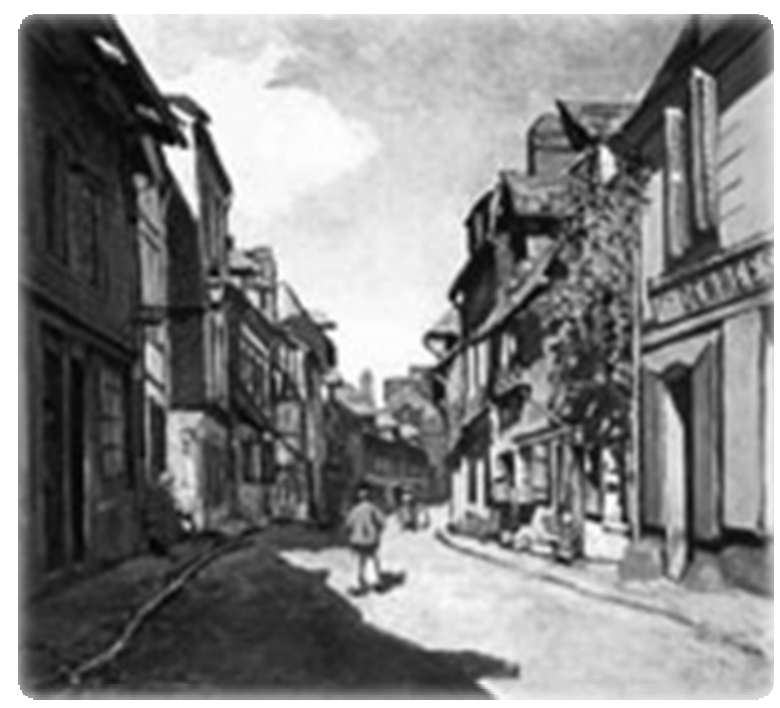

Gambar 4 Rue de la Bavolle, 1864, Claude Monet

\section{Pola dan Testur}

Fungsi lain garis dalam dunia seni adalah untuk menciptakan pola (pattern) dan tekstur (texture). Kembali pada contoh karya Van Gogh di awal, kita melihat kumpulan garis-garis pendek pada permukaan baju yang dikenakan memberi kesan tekstural (kualitas permukaan). Begitu pula goresan-goresan cat pada bagian wajah, rambut, bahkan pada bagian latar, perbedaan intensitas tarikan garis dan juga komposisi warna memberikan kesan kualitas permukaan yang berbeda. Dalam hal ini, Van Gogh telah menghadirkan 'kesan' permukaan (artificial texture), bukan kualitas permukaan berdasarkan sensasi rabaan atau sentuhan indera (natural texture).

\section{Shading dan Modeling}

Salah satu fungsi terpenting garis, terutama dalam dunia menggambar dan cetak, adalah untuk menciptakan kesan bayangan (shade). Shading menjadi hal yang sangat alami pada media pensil. Hal ini tidak dapat dilakukan oleh media lain seperti tinta.

Ada tiga teknik dasar dalam penciptaan shade. Pembuatan garis-garis (hatching) parlalel yang saling berdekatan adalah salah satu cara paling sederhana. Garis bersilang (cross hatching). Teknik ini mendekati dengan teknik yang pertama di atas, namun pada teknik ini, antargaris saling bersilangan. Teknik yang ketika dikenal dengan sebutan stippling, yaitu teknik pembuatan bayangan dengan cara membuat titik-titik dengan perbedaan intensitas jarak. Kadang tujuan dari shading adalah untuk menciptakan ilusi tiga dimensional pada permukaan datar. 


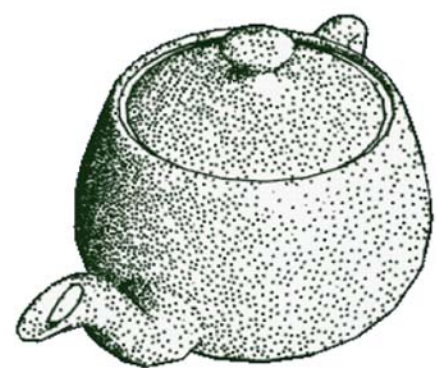

Gambar 5. Stipling

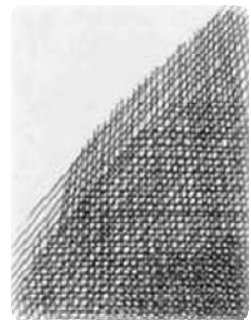

Gambar 6. Cross Hatching

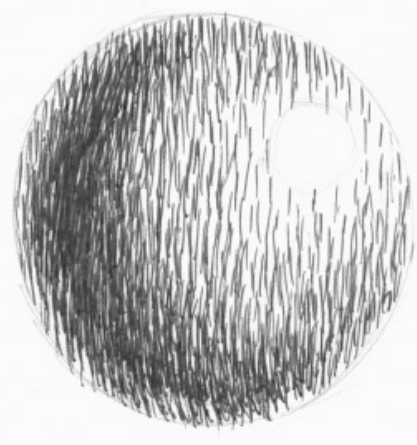

Gambar 7 Hatching

\section{Bentuk (Shape) dan Massa (Mass)}

Bentuk adalah area dua dimensional dengan batasan yang dapat dikenal, atau bisa juga diartikan sebagai garis yang menutup (close line). Massa adalah wujud tiga dimensional yang 'padat' dengan batasan yang dapat dikenali. Definisi ini benar, dan akan menjadi masuk akal bagi siapa saja yang mendalami ilmu geometri. Lingkaran dan segi empat adalah bentuk; bulatan / bola dan kubus adalah massa. Sejauh ini masih belum ditemukan masalah. Kebingungan kemudian muncul ketika kita mencoba untuk melewati atau melampaui pernyataan ini, dengan dua alasan. Pertama, ada sedikit konsistensi dalam cara penggunaan istilah tersebut dalam kehidupan sehari-hari; orang dengan mudahnya mengatakan sesuatu dengan wujud tiga dimensional dengan sebutan "bentuk" (shape). Kedua, paling tidak ada dua istilah lain-form dan volume-yang memiliki makna yang hampir sama. Mencari pengertiannya dalam kamus tidak akan banyak membantu, karena masing-masing kata tersebut akan saling menerjemahkan. Sebagai contoh:

Massa: wujud tiga dimensional bentuk dan volume

Shape: karakter datar dari sebuah form (bentuk)

Form: bentuk (shape) dari sesuatu atau seseorang; kualitas tiga dimensional atau volume Volume: massa atau kuantitas.

Semua pengertian diatas nampaknya menjadi hanya berkutat dalam definisi yang sama. Dalam bahasa Indonesia, shape dan form memiliki problematika yang tidak ada habisnya, sangat menarik untuk dianalisis. Sebagian besar dari kita memahami kedua istilah tersebut dalam pengertian yang sangat sederhana; keduanya merujuk pada kata "bentuk".

Shape dapat diartikan sebagai "lekuk", sebuah pengertian yang paling asal dan abstrak. Belum dapat merujuk pada pengertian "wujud". Untuk lebih mempermudah, shape merujuk pada sesuatu yang dua dimensional (flat). Ketika shape telah memiliki volume (sumbu $X$ dan sumbu $Y$ ). Form; bagaimana sebuah karya seni disusun (composed) secara struktural berdasarkan fungsinya dan tujuan ekspresifnya, yang berakibat pada kegunaan dan maknanya.

Shape adalah area dua dimensional, dapat tercipta dari garis, warna, kekontrasan kualitas permukaan (texture), atau oleh kombinasi semuanya. Jika seseorang menarik garis melingkar, kemudian mengisinya dengan warna merah, maka hasilnya adalah sebuah bentuk lingkaran berwarna merah. Bahkan ketika tidak ada garis yang hadir, hanya berupa tarikan kuas dengan cat berwarna merah membentuk lingkaran, kita akan tetap menerima dan menerjemahkannya sebagai bentuk lingkaran berwarna merah. 
Massa (mass) adalah bentuk padat tiga dimensional, memiliki kedalaman ruang yang nyata. Sebagai contoh, misalnya, Apel adalah sejenis buah-buahan yang memiliki massa berbentuk apel. Kadang kata massa memiliki implikasi jumlah, kepadatan, dan berat.

Volume memiliki pengertian yang mirip dengan massa. Walau kadang bisa merujuk pula pada pengertian sesuatu yang kosong, sebuah ruang kosong tapi tertutup, sedangkan massa merujuk pada sesuatun yang solid/padat. Sebagai contoh, ketika kita melihat deretan batu Stonehenge, maka segera saja kita mengacu pada massa-nya atau pada volume-nya. Seperti juga pada bangunan Museum Guggenheim, kita akan membicarakan persoalan volume bangunan tertutup yang tercipta dari susunan struktur.

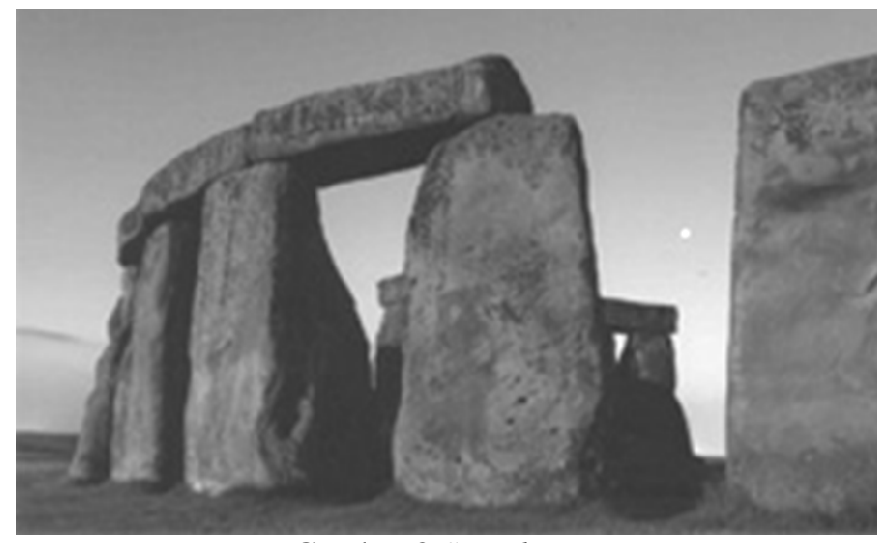

Gambar 8 Stonehenge

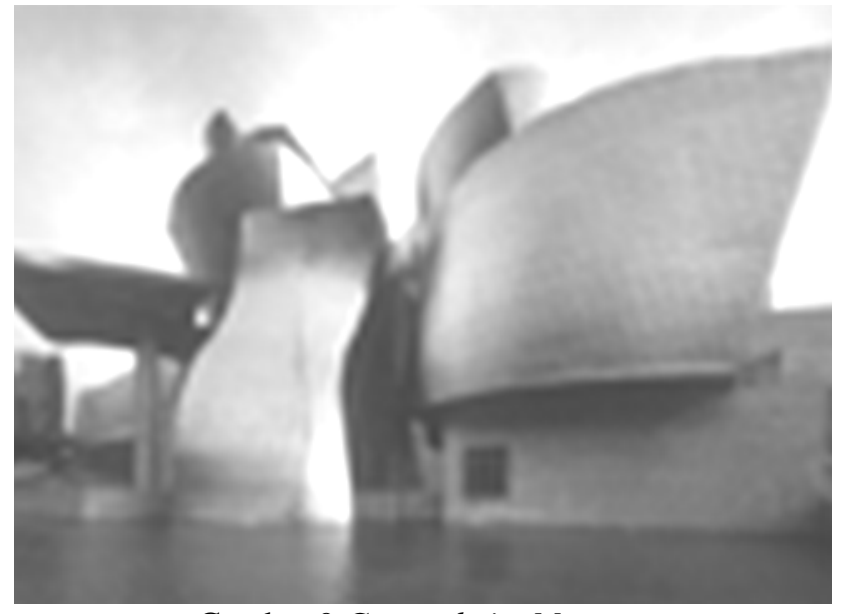

Gambar 9 Guggenheim Museum

Bentuk (form) dapat dikatakan sebagai istilah yang paling rumit dari kesemuanya karena memiliki begitu banyak pengertian atau makna. Hal itu dapat berarti shape, atau juga mass. Bisa berarti komposisi atau struktur, atau bahkan gaya (style). Dalam hubungannya dengan persoalan elemen visual, pembahasan akan dibatasi pada istilah shape dan mass. Keduanya memiliki pengertian dan definisi yang paling 'terbatas' dan paling mudah untuk dianalisis.

Seorang seniman yang mendedikasikan karyanya bagi kepentingan studi bentuk geometris adalah seorang pelukis Belanda, Piet Mondrian. Karya Mondrian, Composisition with Red, Yellow, and Blue adalah tipikal karyanya yang matang dan merepresentasikan pencarian sang seniman terhadap yang dia sebut sebagai “realitas sejati” (pure reality). Mondrian berpendapat bahwa beberapa hal adalah universal sifatnya, umum dan lumrah bagi semua orang, - persegi panjang, garis vertikal 
dan horizontal, warna-warna primer, merah, kuning, biru, ditambah hitam dan putih. Melalui ini, dia berharap dapat memotong perbedaan kebudayaan dan emosional di antara masyarakat dan membuat pernyataan visual yang dapat bermakna bagi semua manusia. Kanvas Mondrian nampak begitu sederhana, terbagi dalam satu garis, mengubah dimensi dari persegi panjang, mengubah satu area warna, dan keseluruhan komposisi nampak berantakan - itulah keseimbangan dinamis yang diperoleh Mondrian dengan bentuk-bentuk geometrisnya.

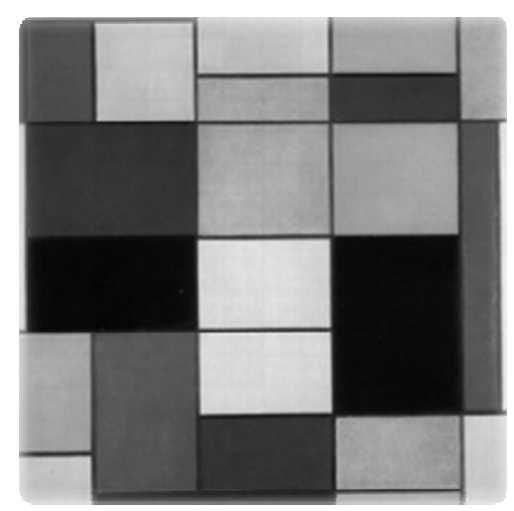

Gambar 10 Piet Mondrian, Composition with Red, Yellow, and Blue

Bentuk-bentuk organik juga muncul pada karya Joan Miro, the Garden, sebuah pemandangan taman, dengan kehadiran wujud-wujud berbentuk bunga, burung, unggas, mungkin tampak juga burung yang sedang terbang, kupu-kupu, bahkan siput yang tercipta dari bentuk-bentuk dasar dan komposisi warna yang begitu hangat. Di sini Miro hanya memanfaatkan bentuk disertai permainan warna.

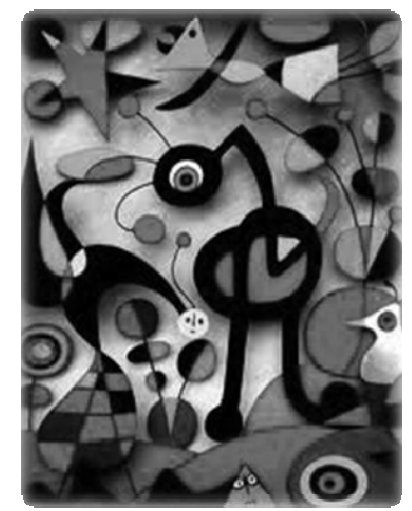

Gambar 11 Joan Miro, the Garden

Pada karya Michaelangelo, Study for Libyan Sibyl, nampak sekali pemanfaatan teknik arsir yang sangat kuat, sehingga menghasilkan kesan shade atau bayangan yang begitu natural. Medium tiga dimensional hadir dengan begitu alaminya pada permukaan datar. Perpaduan antara sensitifitas arsir dengan pemahaman bentuk (shape) yang sangat mendalam, dieksekusi dengan tingkat keberhasilan di atas rata-rata, yang pada akhirnya gambar dua dimensional menjadi memiliki massa (mass). Detail lekukan otot yang berkontraksi diakibatkan oleh gesture memutar (twisting) menghadirkan keindahannya tersendiri. Logika bayangan menjadi begitu wajarnya. Dalam hal ini, contoh karya tersebut dapat menjadi bukti bagaimana guratan-guratan garis dapat menjawab persoalan shade, shape dan mass. 


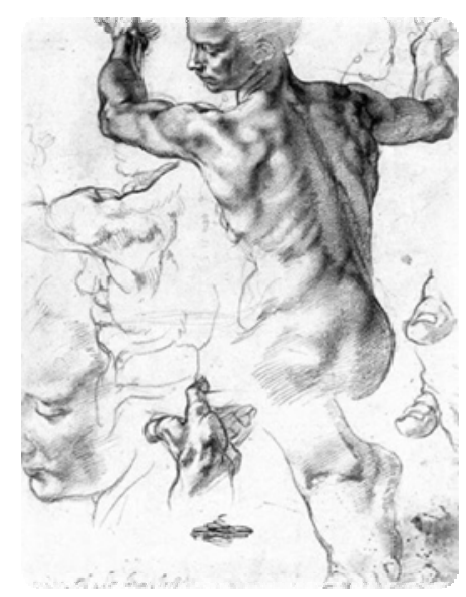

Gambar 12 Michaelangelo, Study for Libyan Sibyl

Sebelum kita mengakhiri bahasan tentang bentuk dua dimensional, baiknya kita sedikit menyentuh juga salah satu aspeknya, yaitu konsep ruang positif /negatif (positive / negative space), kadang dikenal dengan sebutan hubungan figur-latar (figure-ground relationship). Sebuah lukisan atau karya seni dua dimensional lainnya kadang memiliki satu bahkan lebih bentuk yang dapat diartikan sebagai area positif. Dalam karya representasional, itu semua adalah bentuk dari subjeknya; dalam karya non-representasional, itu semua adalah bentuk-bentuk yang nampak aktif dan dominan. Sebagai contoh, pada karya Van Gogh, figure foto diri Vincent Van Gogh adalah bentuk positif (positive shapes) figure dari lukisan. Lainnya adalah bentuk negative (negative shape), atau latar. Jika dibandingkan dengan karya M.C. Escher, kita akan kesulitan untuk menemukan manakah bentuk positif dan bagian manakah bentuk negatifnya. Fokuskan mata kita pada area yang gelap, dan bagian yang terang menjadi latar; fokus pada bagian yang terang, maka bagian gelap akan menjadi latar. Escher memperuntukkan karyanya menjadi sebuah puzzle visual.

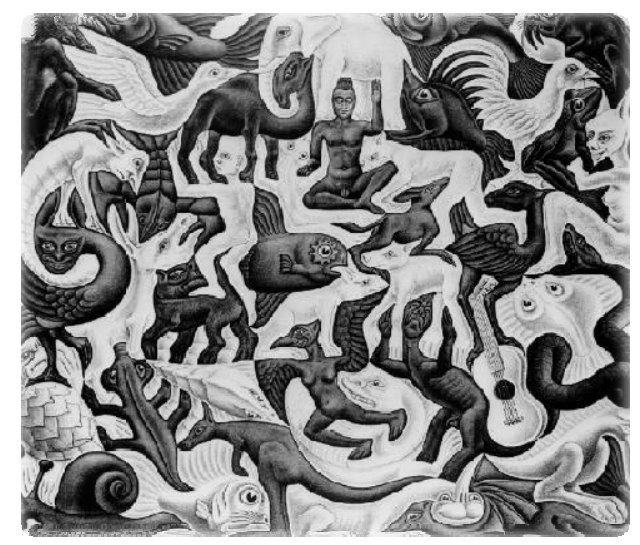

Gambar 13 M.C. Escher

Mungkin tidak ada elemen visual yang paling besar dampaknya pada karya seni selain bentuk (shape) dan massa (mass). Ketika kita menjelaskan sebuah karya seni, biasanya hal pertama yang kita bicarakan adalah bentuk. Tiga elemen lainnya pun tentu saja sangat krusial peranannya, dalam memengaruhi respons kita terhadap seni. 


\section{SIMPULAN}

Bagi seorang desainer visual, elemen visual (dot \& line, shape, mass/volume, space, color \& value, type/text, image, texture) sama seperti notasi bagi seorang musisi, atau kata-kata bagi seorang penulis. Semua itu adalah perangkat bagi mereka untuk menciptakan sebuah karya masterpiece. Elemen visual merujuk pada "apa” yang dipakai, sedangkan prinsip desain tentang bagaimana memakainya. Pada tulisan di atas, penulis hanya membatasi pembahasan penerjemahan dan aplikasi elemen visual pada karya-karya seni. Kehadiran semua elemen visual di atas sangat menentukan bagi hadirnya sebuah karya seni (artifact). Garis, bentuk, gerak, bayangan, massa, volume adalah kata yang begitu umum, menjadi khusus ketika diaplikasikan dalam lingkup seni atau desain. Berdasarkan fungsinya masing-masing, setiap elemen tersebut disusun menjadi sebuah rangkaian "bahasa"; bahasa visual. Proses dialog antara seniman/desainer - karya - audiens/penikmat dapat terjadi secara cair apabila semua elemen visual disusun dan dikordinasi dengan pertimbangan yang matang. Seorang seniman dan desainer adalah seorang "form giver", seseorang yang memberikan makna pada sebuah bentuk abstrak. Ketika seorang seniman atau desainer dihadapkan pada sebuah material atau medium tertentu, maka kemampuan teknis, konseptual dan estetisnya akan bekerja agar medium tersebut menjadi lebih bermakna atau memiliki fungsi. Seorang seniman atau desainer adalah seorang "problem solver". Melalui kemampuannya dia dapat memberikan solusi visual terhadap segenap permasalahan, atau paling tidak dapat memberikan inspirasi pada audiensnya.

\section{DAFTAR PUSTAKA}

Danesi, Marcel. (2004). Messages, Signs and Meanings. Toronto: Canadian Scholar’s Press Inc.

De La Croix, Horst, Tansey, Richard G., Kirkpatrick, Diane. (1987). Art Through the Ages. Fort Worth: HBJ-Harcourt Brace Jovanovich College Publisher.

Lauer, David A., Pentak, Stephen. (1994). Design Basic. Ohio: Thomson Wadsworth.

Lester, Paul Martin. (2003). Visual Communication Image with Messages. California: Thomson Wadsworth.

Meggs, Phillip. B. (1998). A History of Graphic Design. Canada: John Wiley and Sons, Inc.

Zeegen, Lawrence. (2005). The Fundamentals of Illustration. Switzerland: AVA Book Publishing.

http://www.artinthepicture.com/

http://www.rsc.org/chemsoc/visualelements/

http://www.princetonol.com/groups/iad/Files/elements2.htm

incredibleart.org

http://photoinf.com/General/Robert_Berdan/Composition_and_the_Elements_of_Visual_Design.htm http://learn.midsouthcc.edu/learningObjects/art/pdf/Unit3AVocabScriptVisualElements.pdf 